\title{
Photovoltaic Panels Temperature Regulation Using Evaporative Cooling Principle: Detailed Theoretical and Real Operating Conditions Experimental Approaches
}

\author{
Zeyad A. Haidar $1,2,3, * \mathbb{D}$, Jamel Orfi ${ }^{4,5}$ and Zakariya Kaneesamkandi 4 (D) \\ 1 Electrical Engineering Department, College of Engineering, King Saud University, \\ Riyadh 11421, Saudi Arabia \\ 2 Sustainable Energy Technologies Center, College of Engineering, King Saud University, \\ Riyadh 11421, Saudi Arabia \\ 3 Electrical Engineering Department, College of Engineering, Aden University, Aden 6312, Yemen \\ 4 Mechanical Engineering Department, College of Engineering, King Saud University, \\ Riyadh 11421, Saudi Arabia; jorfi@ksu.edu.sa (J.O.); zkaneesamkandi@ksu.edu.sa (Z.K.) \\ 5 KA.CARE Energy Research and Innovation Center Riyadh, Riyadh 11451, Saudi Arabia \\ * Correspondence: zhaidar@ksu.edu.sa
}

Citation: Haidar, Z.A.; Orfi, J.; Kaneesamkandi, Z. Photovoltaic Panels Temperature Regulation Using Evaporative Cooling Principle: Detailed Theoretical and Real Operating Conditions Experimental Approaches. Energies 2021, 14, 145. https://doi.org/10.3390/en14010145

Received: 6 December 2020 Accepted: 23 December 2020 Published: 29 December 2020

Publisher's Note: MDPI stays neutral with regard to jurisdictional clai$\mathrm{ms}$ in published maps and institutional affiliations.

Copyright: $\odot 2020$ by the authors. Licensee MDPI, Basel, Switzerland. This article is an open access article distributed under the terms and conditions of the Creative Commons Attribution (CC BY) license (https:// creativecommons.org/licenses/by/ $4.0 /)$.

\begin{abstract}
Solar photovoltaic (PV) applications are gaining a great interest worldwide and dominating the renewable energy sector. However, the solar PV panels' performance is reduced significantly with the increase in their operating temperature, resulting in a substantial loss of energy production and poor economic scenarios. This research contributes to overcoming the PV performance degradation due to the temperature rise. This work involves experimental and theoretical studies on cooling of PV panels using the evaporative cooling (EC) principle. A new EC design to cool the bottom surface of a PV panel was proposed, fabricated, tested, and modeled. A series of experimentation readings under real conditions showed the effectiveness of the method. A steady state heat and mass transfer model was implemented and compared with the experimental data. Fair agreement between the results of the modelling and experimental work was observed. It was found that the temperature of the PV panel can be decreased by $10{ }^{\circ} \mathrm{C}$ and the power improvement achieved was $5 \%$. Moreover, the EC helps to stabilize the panels' temperature fluctuation, which results in a better regulation of electrical power output and reduces the uncertainty associated with solar PV systems.
\end{abstract}

Keywords: PV performance; evaporative cooling; temperature; solar; heat and mass transfer

\section{Introduction}

Under the pressure of increasing electrical energy demand and depleting fuels, renewable energy, and especially solar photovoltaic (PV) technology, represent one of the solutions because of the attractive economic and environmental features of these resources. Installing PV panels is becoming essential for governmental, industrial, and domestic sectors for the present and future energy requirements. In 2019, $578 \mathrm{GW}_{\mathrm{p}}$ of solar PV was installed worldwide [1]. However, the actual output of the installed solar PV is drastically degraded due to some environmental factors. Temperature and dust are the main two factors that lower the actual output and badly affect the PV panels' performance. Consequently, many methods have been proposed to manage the temperature problem by cooling the PV panels. The principal cooling methods can be broadly classified as single phase (sensible heat) methods and phase change (latent heat) ones. These include:

1. Cooling by natural and forced air $[2,3]$.

2. Cooling by water [4-6].

3. Cooling by phase change materials (PCM) $[7,8]$.

4. Cooling by evaporation of liquids [9-11]. 
Recently, S.R. Abdallah et al. used saturated zeolite with water for PV cooling and a $9{ }^{\circ} \mathrm{C}$ temperature reduction was achieved [12]. Other techniques were also proposed for cooling PV panels such as thermoelectric cooling [13] and radiative cooling [14]. A comprehensive review of these and other techniques that have been proposed for PV cooling is available in [15-17]. Among these technologies, evaporative cooling (EC) which is very effective especially in dry climates-has received very little attention. The EC principle is well-known and widely employed in many industrial and residential applications. However, its use for cooling PV panels is very rare. The thermal and electrical efficiency of PV panels using water cooling and active clay pot evaporative cooling methods has been investigated by Rankumar et al. [18]. The advantages of using the evaporative cooling principle are clearly shown. Alami [11] studied the effect of evaporative cooling on the efficiency of the PV modules. His method incorporated a layer of synthetic clay to the back of the module and allowing a thin film of water to evaporate. The results show that a maximum increase of $19.4 \%$ in the output voltage and $19.1 \%$ in the output power can be obtained.

Drabiniok and Nayer [19] proposed a new PV cooling device based on a bionic evaporation foil made of a porous compound polymer. Details of the fabrication and performance of the proposed cooling device have been highlighted. The results show that a temperature reduction of about $12{ }^{\circ} \mathrm{C}$ can be reached. A good potential for further enhancement is reported.

PV EC using the chimney effect integrated with a solar chiller to enhance the performance has been investigated experimentally by Lucas et al. [20]. The results reveal that the $\mathrm{PV}$ module temperature difference can reach $8{ }^{\circ} \mathrm{C}$ while the average improvement in the module electrical efficiency can be about $7.6 \%$ in a typical day with Mediterranean weather. In a recent study, a modified version of the evaporative PV chimney using water sliding was presented, showing an average cooling of the PV module of $15^{\circ} \mathrm{C}$ resulting in about $15 \%$ improvement in the electrical efficiency [21].

Despite the effectiveness of EC, which explains its wide applications in the industrial sector, the number of studies on using EC in PV cooling is very few, as this review shows. Furthermore, a detailed performance study of this method and its dynamic behavior have not been conducted systematically. Additionally, there are only few experimental studies using EC under real operating conditions. Likewise, there are limited models for simulating simultaneous heat and mass transfer in cooling of PV using EC. Hence, this work attempts to fill these scientific gaps in this field by introducing a new design that implements the evaporation cooling phenomenon to tackle the temperature rise problem in PV panels. This work presents a comprehensive theoretical and experimental study along with a performance study on various parameters that affect the effectiveness of the proposed PV cooling method. This study was carried on under real harsh environmental conditions over several days to ensure the reliability and repeatability of the results. Short-term and long-term results are presented and investigated.

The following sections describe the theoretical heat and mass transfer model and the experimental setup. The obtained experimental and theoretical results are presented and discussed.

\section{Modeling}

This section presents a model of the heat and mass transfer for evaporative cooling occurring in a rectangular channel with parallel plates used to cool the bottom surface of a PV panel.

\subsection{Model Description}

The physical model consists of an inclined duct in which the upper surface is a PV panel. The dimensions of the duct are: $3 \mathrm{~cm}$ height, $140 \mathrm{~cm}$ long and $67 \mathrm{~cm}$ width. On the lower side of the duct, water flows on a piece of cloth that functions as a water distributor. Air is blown inside the duct by a fan in the same direction as the water flow (co-current 
configuration). A schematic diagram on the considered physical model is shown in Figure 1. The lower surface of the duct is adiabatic. On the top surface, the PV panel is subjected to a uniform solar radiation intensity with heat losses to the ambience. As air flows over the wetted surface inside the duct, water evaporates and cools the air, which, in turn, absorbs the heat from the PV panel body. Since the heat is transferred to the flowing air, the temperature of the PV panel decreases, and electricity production enhances.

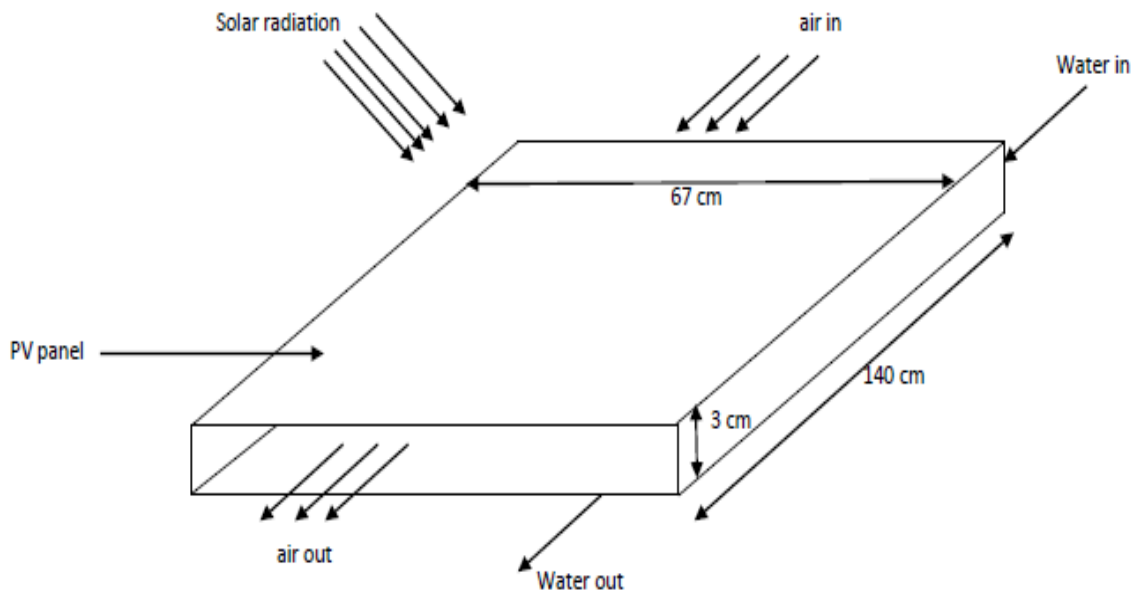

Figure 1. Schematic diagram for the photovoltaic (PV) panel with evaporative cooling.

\subsection{Modelling}

A uni-dimensional steady state model of heat and mass transfer is used in this work. This model assumes the following: (1) a mass-less layer of saturated gas between the liquid and air exists, (2) the heat and mass transfer coefficients are constants, and (3) the air and water vapor are ideal gases and their specific heat capacities are independent of temperature. The temperatures of air, water, interface saturated layer and PV panel change in the flow direction (x axis). The physical model described schematically in Figure 1 can be simplified and reduced to an inclined channel composed of two parallel plates. The upper surface of the lower plate is covered with a thin layer of water while its lower surface is maintained adiabatic. The bottom surface of the PV panel is cooled with air that is in direct contact with the water layer.

Ambient air enters the channel at known conditions of temperature, humidity, and mass flow rate $\left(T_{a i}, w_{i}\right.$ and $\left.\dot{m}_{a}\right)$. It exchanges heat and mass with the water layer as well as the solar PV back surface. The PV panel receives solar radiation $G$ and also exchanges heat with ambience.

The present model is based on a previous model developed by Boulama et al. [22] for the heat and mass transfer between a wetted surface and a gas stream flowing in a duct. It assumes the existence of a very thin film of saturated air between the water and gas streams. The temperature and mass flow ratio for this mass-less layer depend on the axial position but are related by the appropriate saturation equation corresponding to the line for $100 \%$ relative humidity on the psychrometric chart. The solar radiation gained by the PV panel and the heat losses to its surrounding are included in the present model.

Energy balances on the PV panel, air, and water layers as well as the water mass balance form the main governing equations of the model. Figure 2 shows a side view of the flow. 


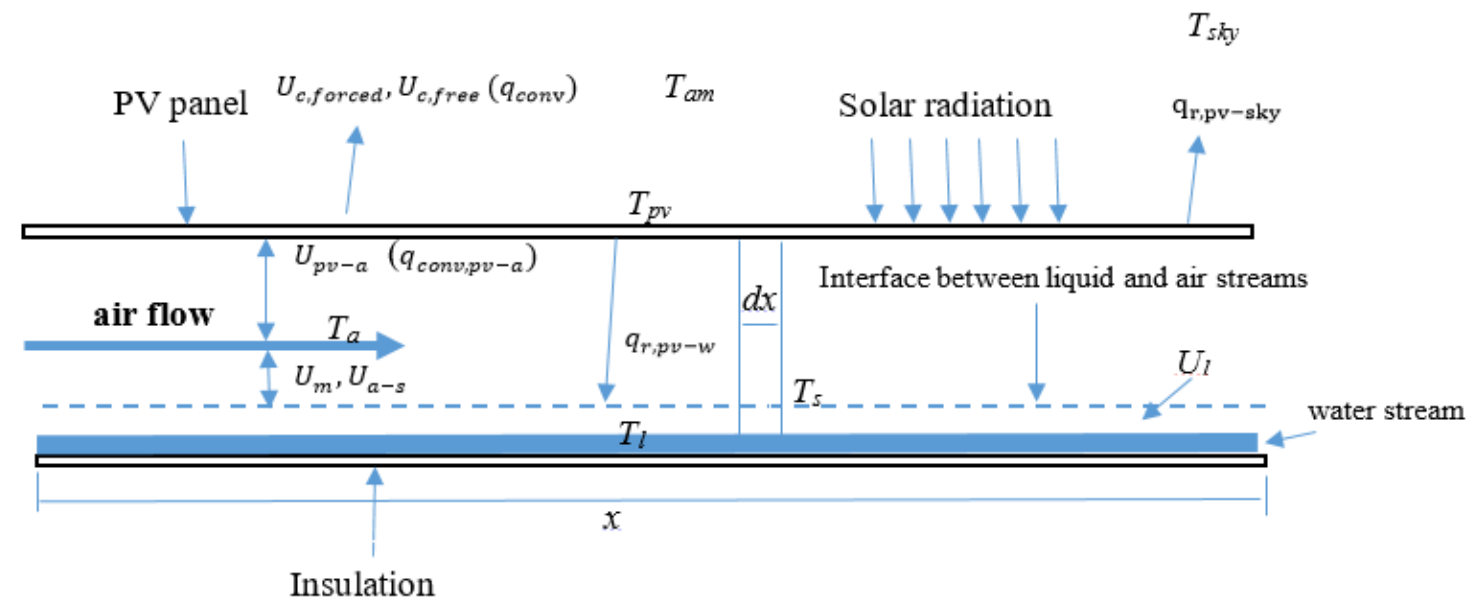

Figure 2. Side view of a heat and mass exchanger with direct contact between a binary gas mixture and a liquid.

Air enters at temperature $T_{a i}$ and exchanges heat with PV panel with heat transfer coefficient $U_{p v-a}$ and with saturation interface layer with heat transfer coefficient $U_{a-s}$. Mass transfer occurs between air and the interface layer with mass transfer coefficient $U_{m}$. Heat transfer also occurs between the water and the interface layer with a heat transfer coefficient $U_{l}$. The following equations give the energy balance for each layer.

$$
U_{a-s} P\left(T_{s}-T_{a}\right)+\dot{m}_{a} \frac{d w}{d x} C_{p, v}\left(T_{s}-T_{a}\right)+U_{p v-a} P\left(T_{p v}-T_{a}\right)=\dot{m}_{a}\left(C_{p, a}+w C_{p, v}\right) \frac{d T_{a}}{d x}
$$

where $P$ is the panel width and $C_{p, a}$ and $C_{p, v}$ are the specific heat capacity of air and water vapor.

Equation (1) represents the axial change in temperature of flowing air inside the duct. The first term represents the heat transfer between the interface layer and flowing air. The second term concerns the heat transfer associated with the change in the humidity ratio of the flowing air due to mass transfer where $\dot{m}_{a}$ is the air mass flow rate. The third term gives the heat transfer between the bottom surface of the PV panel and the flowing air. The interface saturation layer reacts with flowing air and water, and its temperature is given by:

$$
U_{a-s} P\left(T_{a}-T_{s}\right)+U_{l} P\left(T_{l}-T_{s}\right)=\dot{m}_{a} h_{f g} \frac{d w}{d x}
$$

where $h_{f g}$ is the enthalpy of evaporation of water, and $\frac{d w}{d x}$ is the change of vapor concentration in the flowing air. The water temperature inside the duct changes, as well, with air flow and this is given by the following equation:

$$
U_{l} P\left(T_{s}-T_{l}\right)=\dot{m_{l}} C_{p, l} \frac{d T_{l}}{d x}
$$

where $\dot{m}_{l}$ is the liquid (water) flow rate and $C_{p, l}$ is the liquid specific heat capacity. The change in the water concentration in the flowing air is accounted for by the following equation:

$$
\dot{m}_{a} \frac{d w}{d x}=U_{m} P\left(W_{s}-w\right)
$$

where $U_{m}$ is the mass transfer coefficient in $\mathrm{kg} / \mathrm{m}^{2} \mathrm{~s}$ and $W_{s}$ is the saturation humidity evaluated using the following equation [2]:

$$
W_{s}=\left(7.17-0.29 T_{s}+0.0333 T_{s}^{2}\right) 10^{-3}
$$


The value of $U_{m}$ is obtained from the heat transfer coefficient $U_{a-s}$ and Lewis number $L e$, according to the following equation [22]:

$$
L e=U_{a-s} / U_{m}\left(C_{p, a}+W C_{p, v}\right)
$$

To deduce the energy balance equation, various energy transfer mechanisms must be identified. First, the convection heat transfer between the PV panel with temperature $T_{p v}$ and ambient air with $T_{a m}$ has three components: forced convection between PV panel and ambient air due to wind flow $U_{c, \text { forced }}$, free convection or natural convection due to buoyancy effects $U_{c, \text { free }}$, and convection between PV panel back surface and air flowing inside the duct $U_{p v-a}$ in the case of the cooled panel. Therefore, the heat convection between PV panels and ambience is:

$$
q_{\text {conv }}=\left(U_{c, \text { forced }}+U_{c, \text { free }}\right)\left(T_{p v}-T_{a m}\right)
$$

There are wide discrepancies in determining the value of $U_{c \text {,forced }}$. Different formulas were proposed in the literature. After systematic investigation and comparing several available correlations in the literature, the following formulas were chosen:

$$
U_{c, \text { forced }}=8.91+2 \mathrm{WS},
$$

where WS is the wind speed [23] and

$$
U_{c, \text { free }}=1.31\left(T_{p v}-T_{a m}\right)^{1 / 3}
$$

According to weather data of wind speed obtained from the weather station on the roof of the mechanical engineering department, the wind direction blows mostly from south to north or north to south. This means that the heat transfer by convection from the PV panel will have both components (free and forced) in the wind flow direction and only one component (free convection) in the opposite direction. In the case of the cooled PV panel that is covered from its back by a duct, heat convection occurs just from one side.

Concerning the third component $U_{p v-a}$, it can be found using the heat transfer correlations after specifying the flow type after determining the value of Reynold's number (Re). The average air velocity inside the duct during the experimentation was around $0.8 \mathrm{~m} / \mathrm{s}$. This flow along with duct dimensions results in a Reynold's number in the range $4000>$ $\operatorname{Re}>2300$, which corresponds to a transition flow regime. Engineering Equation Solver (EES) software was used to find the value of $U_{p v-a}$ using the procedure "DuctFlow_N", which returns the average Nusselt number and friction factor for constant temperature wall and constant heat flux for the given flow condition in a rectangular duct characterized by Reynolds and Prandtl numbers, length/hydraulic diameter, aspect ratio, and relative roughness.

Hence, the heat transfer by convection between the flowing air and the cooled PV panel will be:

$$
q_{c o n v, p v-a}=\left(U_{p v-a}\right)\left(T_{p v}-T_{a}\right)
$$

Radiation heat transfer between PV panels and sky temperature is found using the equation given below:

$$
q_{r, p v-s k y}=\varepsilon_{P V} \sigma\left(T_{p v}^{4}-T_{s k y}^{4}\right)
$$

where $\sigma$ is Boltzmann's constant, $\varepsilon_{P V}$ is the PV panel emissivity and set to be equal to 0.9 , and $T_{\text {sky }}$ is the sky temperature and is estimated using [24]:

$$
T_{\text {sky }}=T_{a m}-20
$$


Another radiation heat transfer exists between the cooled PV panel and the wetted cloth inside the duct and is found by:

$$
q_{r, p v-l}=\varepsilon_{P V} \sigma\left(T_{p v}^{4}-T_{s}^{4}\right)
$$

By considering all the equations, the steady state PV panel temperature is found using the following energy balance equation:

$$
G_{s}(\tau \alpha)=q_{r, p v-l}+q_{r, p v-s k y}+q_{c o n v, p v-a}+q_{c o n v}
$$

where $(\tau \alpha)$ is the optical efficiency of the panel and assumed to equal to 0.9. This is for the cooled PV panel. For the PV panel without cooling, the same equation can be used after removing the first and third terms in the above equation. Finally, it should be noted that this analysis assumes that no electrical load is connected to the panel. If electrical load is connected, another term must be added that accounts for the electrical power that is withdrawn from the PV panel.

\section{Experimentation Setup}

Figure 3 shows the cooling experiment set up. The panel on the right (no. 2) is the upper surface of a duct of $3 \mathrm{~cm}$ depth, $140 \mathrm{~cm}$ length and $67 \mathrm{~cm}$ width. There is an entrance section (no. 1) and an exit section (no. 3) of lengths equal $5 \sqrt{ } H P$ and $2.5 \sqrt{ } H P$, respectively, according to ASHRAE standards 93-77 to ensure uniform distribution of air inside the duct, where $H$ is height of the duct and $P$ is its width. The entrance section is thermally insulated from above to prevent the solar radiation heating up air in that section. The test section (no. 2) is thermally insulated from the two edges and the bottom to decrease heat losses. Five thermocouples (TC) of type K, adhered to the PV panel back surface by aluminum tape, were used to measure the temperature of each panel, five TCs for air temperature and five for water. Each set of TCs was distributed longitudinally. The distance between each two TCs was $28 \mathrm{~cm}$. Three TCs were placed at the end of the test section to measure the humidity of the exit air: two TCs for wet bulb temperature and one TC for dry bulb temperature. The weather station (no. 11) was installed to measure weather data, such as wind speed, ambient temperature, and relative humidity.

The air was blown inside the duct by a fan. Under the PV panel, there was a piece of cloth covering the lower side of the duct. This cloth was used to ensure uniform distribution of water that was fed from a water tank (no. 6), passing through a flow meter (no. 7). The water was supplied to the duct at the top of the test section via holes in a feeding rubber tube and absorbed by the cloth. As air flows inside the duct, it comes into contact with the wetted cloth and initiates water evaporation. Due to evaporation, both water and air temperatures decrease. Additionally, while flowing, air contacts the PV panel back surface and hence absorbs heat from it. This, in turn, reduces the panel temperature and hence increases its efficiency.

The panel on the left-hand side (no. 10) is the reference panel used for the sake of comparison. Five TCs are adhered to the back surface of the reference panel in the same way as the cooled panel. First class SR11-05 pyranometer (no. 5) is used to measure the global solar radiation at the same angle of the PV panels. The wooden frame (no. 9) faces the south and has a slope of $24^{\circ}$, which is-approximately-the latitude of Riyadh. The open-circuit voltage of the two panels was measured directly by an Omega-brand data logger. Three data loggers were used to read the sensors readings and transfer data to a laptop.

The specifications of the PV panels that were used in this experimentation are tabulated in Table 1. 


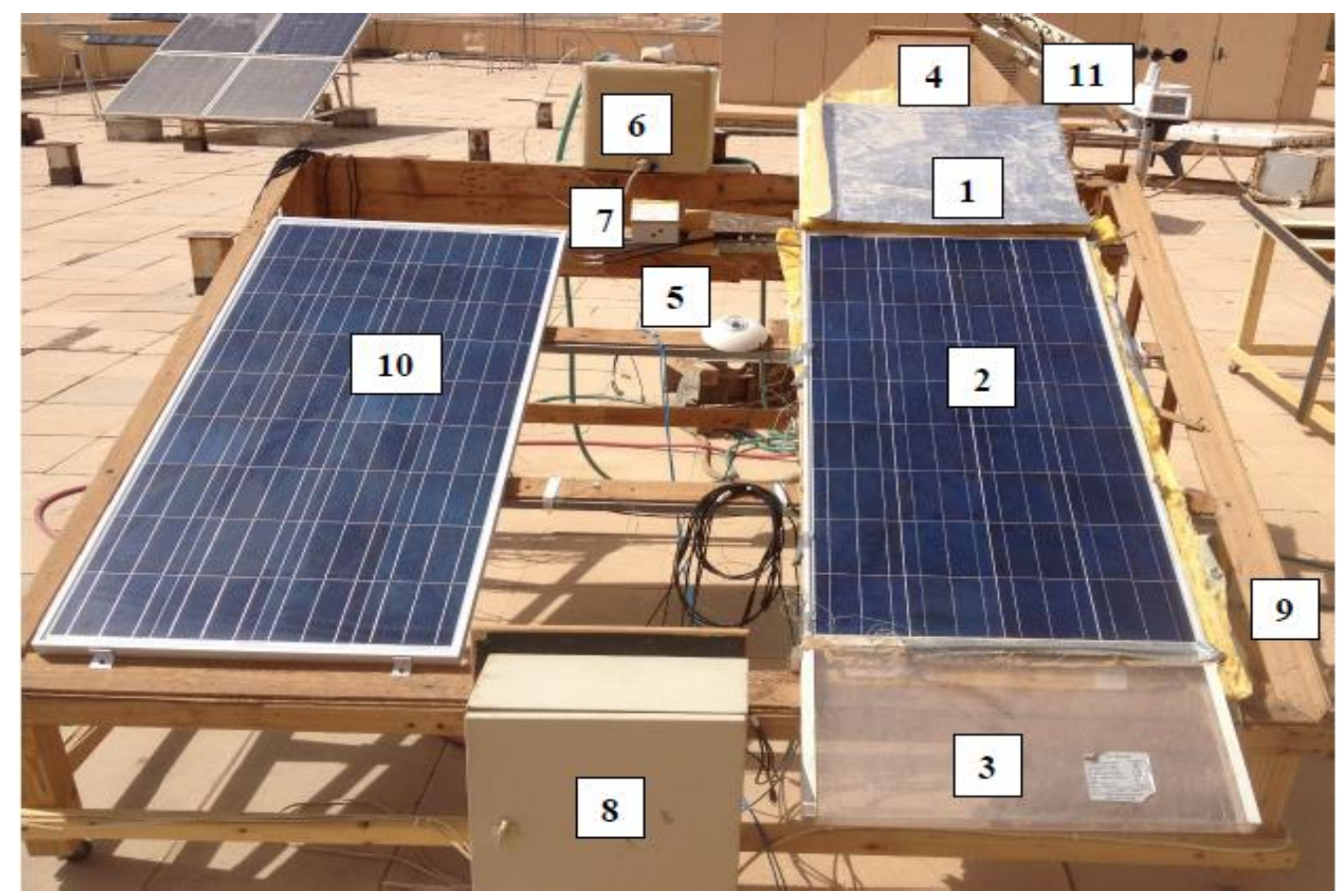

Figure 3. Experiment set up: 1: entrance section, 2: PV panel with cooling, 3: exit section, 4: fan (20W) assembly, 5: pyranometer, 6: water tank, 7: water flow meter, 8: electrical connection box, 9: wooden pool with $24^{\circ}$ inclination facing south, 10: reference panel and 11: weather station.

Table 1. PV panel specifications.

\begin{tabular}{cc}
\hline Parameter & Value \\
\hline Rated power $\left(\mathrm{P}_{\max }\right)$ & $130 \mathrm{~W}$ \\
Volatage at $\mathrm{P}_{\max }\left(\mathrm{V}_{\mathrm{mp}}\right)$ & $17.2 \mathrm{~V}$ \\
Current at $\mathrm{P}_{\max }\left(\mathrm{I}_{\mathrm{mp}}\right)$ & $7.56 \mathrm{~A}$ \\
Open-circuit voltage $\mathrm{V}_{\mathrm{oc}}$ & $21.6 \mathrm{~V}$ \\
Short-circuit current $\mathrm{I}_{\mathrm{sc}}$ & $8.15 \mathrm{~A}$ \\
Voltage temperature coefficient & $-0.3 \% /{ }^{\circ} \mathrm{C}$ \\
\hline
\end{tabular}

\section{Results and Discussion}

\subsection{PV Panels' Temperature}

Outdoor experiments were conducted for several days and the main results of the open-circuit voltage and temperature evolutions of the panels with and without cooling are presented and discussed in this section. Comprehensive sensitivity analysis on the effect of the main influencing parameters such as air and water flow rates was conducted using the developed heat and mass transfer model. Additionally, comparison between the experimental and theoretical results is given in detail.

Figure 4 shows the temperature of the two panels over a period from 11:51 to 14:06 on the 27 June. The dotted curves are the actual readings, and the solid ones are the fitted curves.

As the figure shows, the temperature of the hot reference panel (HPV) reached $73{ }^{\circ} \mathrm{C}$, whereas the temperature of the cooled panel (CPV) did not exceed $65^{\circ} \mathrm{C}$. The average difference between the two temperatures is $\sim 10^{\circ} \mathrm{C}$ and it reached $12{ }^{\circ} \mathrm{C}$ at some instances. Moreover, because of the cooling effect, the fluctuation of the black curve is much less than that of the red one. Figure 5 shows another result for the 30 July. 


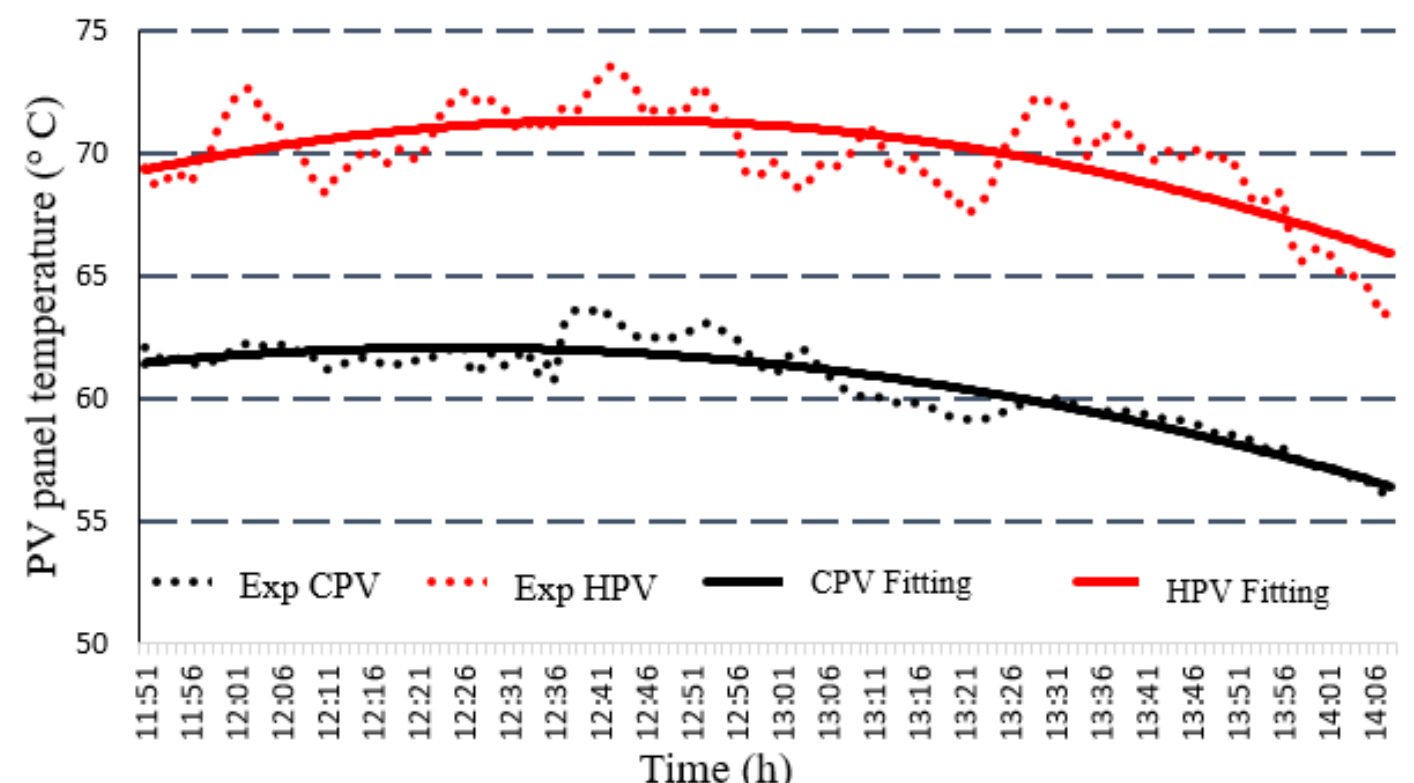

Figure 4. Temperature evolution of the cooled panel (CPV) and reference panel (HPV) at air flow rate $=0.01254 \mathrm{~kg} / \mathrm{s}$ and water flow rate $=0.0083 \mathrm{~kg} / \mathrm{s}$.

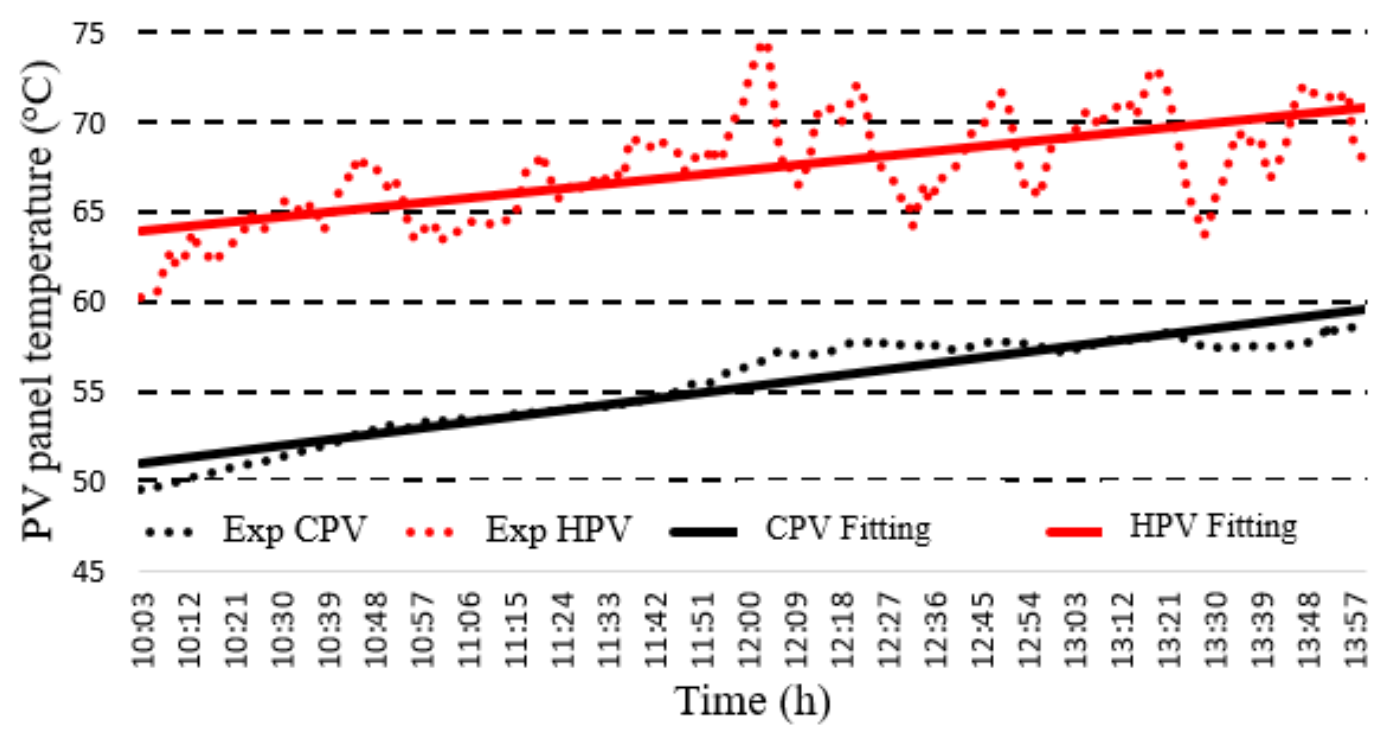

Figure 5. Temperature difference between the cooled panel and reference panel, the 30 July.

\subsection{Electrical Power Improvement}

The open-circuit voltage $\mathrm{V}_{\text {oc }}$ of the two panels is shown in Figure 6 where the black dotted and solid curves represent the actual and fitted values of the cooled PV panel, respectively, and the red dotted and solid curves represent the actual and fitted values of the hot PV panel, respectively. The open-circuit voltage of the cooled panel was elevated by $\sim 0.7 \mathrm{~V}$ at 12:02. Moreover, the voltage of the cooled panel (and hence its power output) is more stable and has less fluctuation than that of the reference panel's voltage.

The stability feature is extremely important from an electric utility point of view because it reduces the solar PV uncertainty and enhances the electric power calculation, such as optimal power flow [25], unit commitment, economic dispatch, generation load balance and quality issues ([26-28]). 


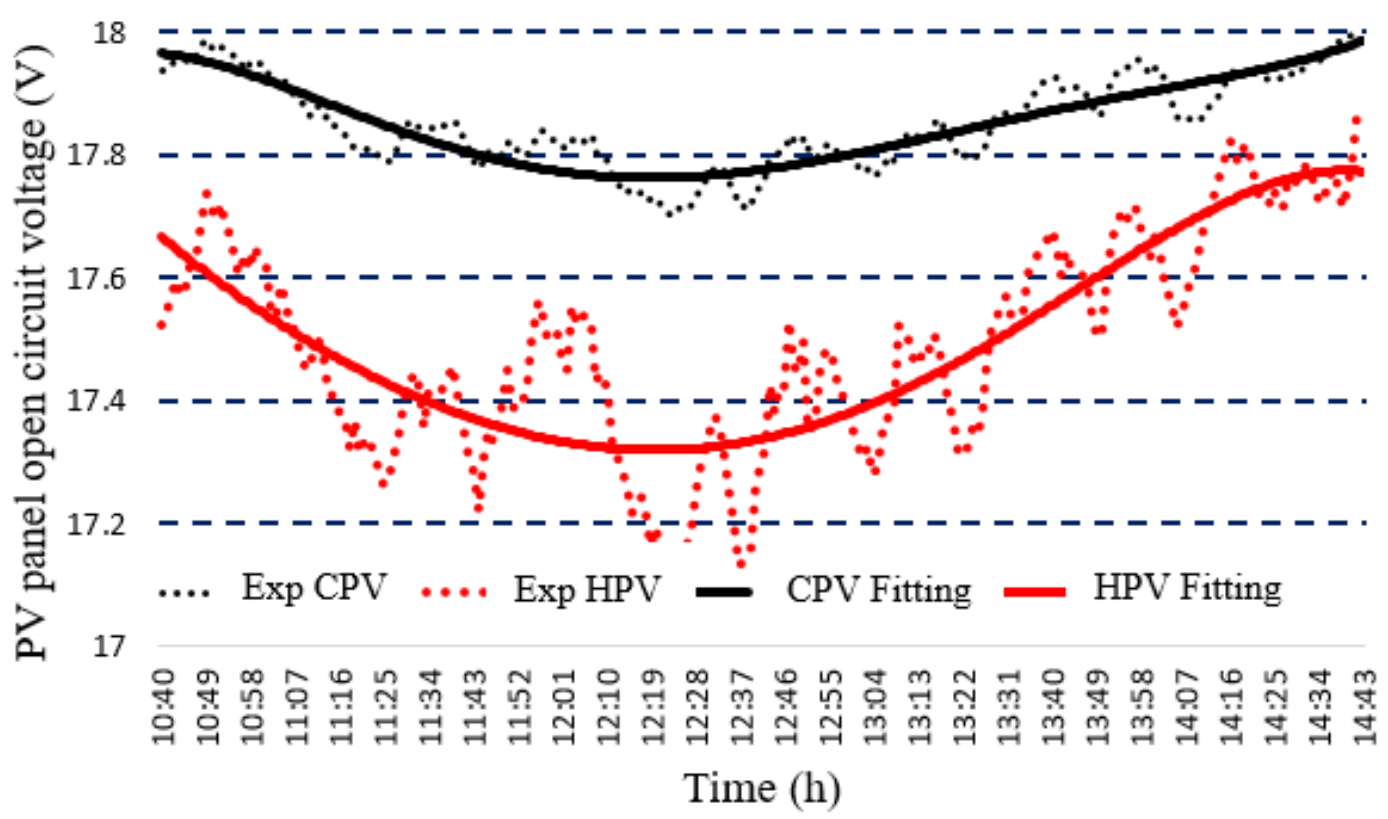

Figure 6. Difference in panels' open-circuit voltages.

This can be clarified more by referring to Figure 7, which depicts the PV powervoltage curve for different temperatures [29]. As the figure shows, the maximum PV power decreases with temperature and therefore the fluctuation of temperature (up and down as shown in Figure 5) yields a fluctuation in PV voltage (Figure 6) and, consequently, a fluctuation in PV output power.

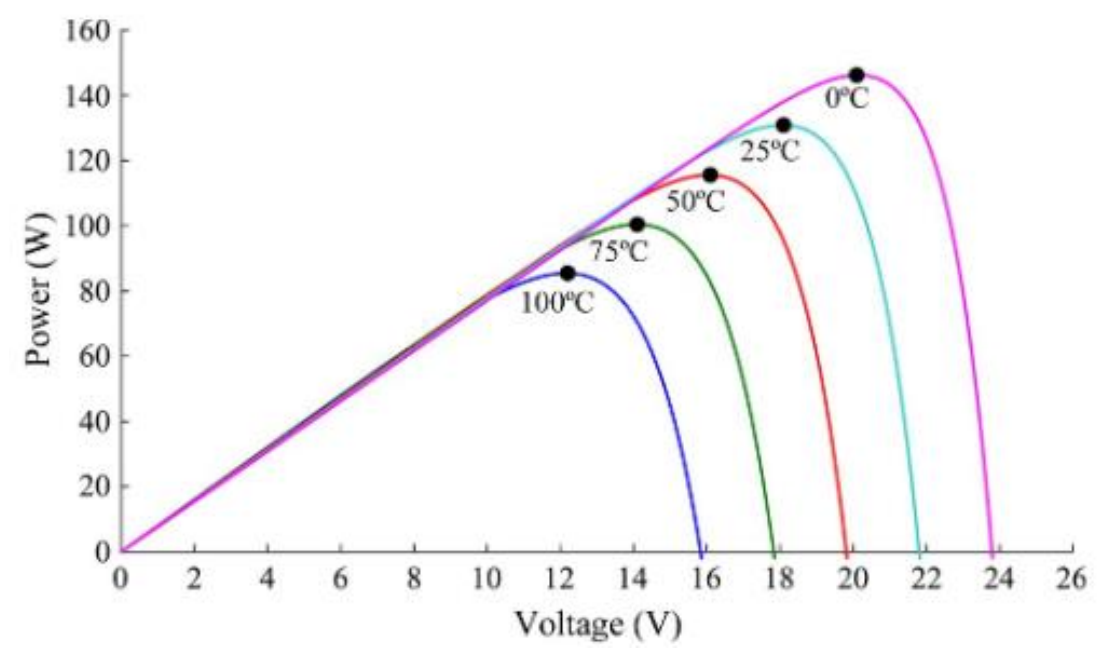

Figure 7. Power-voltage curve of a PV module at different temperatures [29].

Hence, a more stable PV temperature profile (such as the temperature of the cooled panel in Figure 5) results in a more stable PV voltage and output power of solar PV energy sources.

Figure 8 shows the percent of electrical efficiency gain (blue curve with the axis on the right vertical side) associated with the cooling process and the temperature of the two PV panels (the red and black dotted and solid curves with the axis on the left vertical side). The efficiency gain is defined as follows:

$$
\text { Efficiency gain } \%=100 * \frac{\eta_{\text {Cooled PV }-} \eta_{\text {reference PV }}}{\eta_{\text {reference PV }}}
$$


where the efficiency of the PV panels is calculated using the well-known formula:

$$
\eta=\eta_{R}\left[1-\beta\left(T_{\mathcal{c}}-T_{R}\right)\right]
$$

where $\eta_{R}$ is the efficiency at the reference temperature $T_{R}$, which is $25^{\circ} \mathrm{C}, T_{c}$ is the actual temperature and $\beta$ is the efficiency temperature coefficient. The value of $\beta$ was taken as $0.45 \%$ [30]. The average efficiency gain is $6.73 \%$.

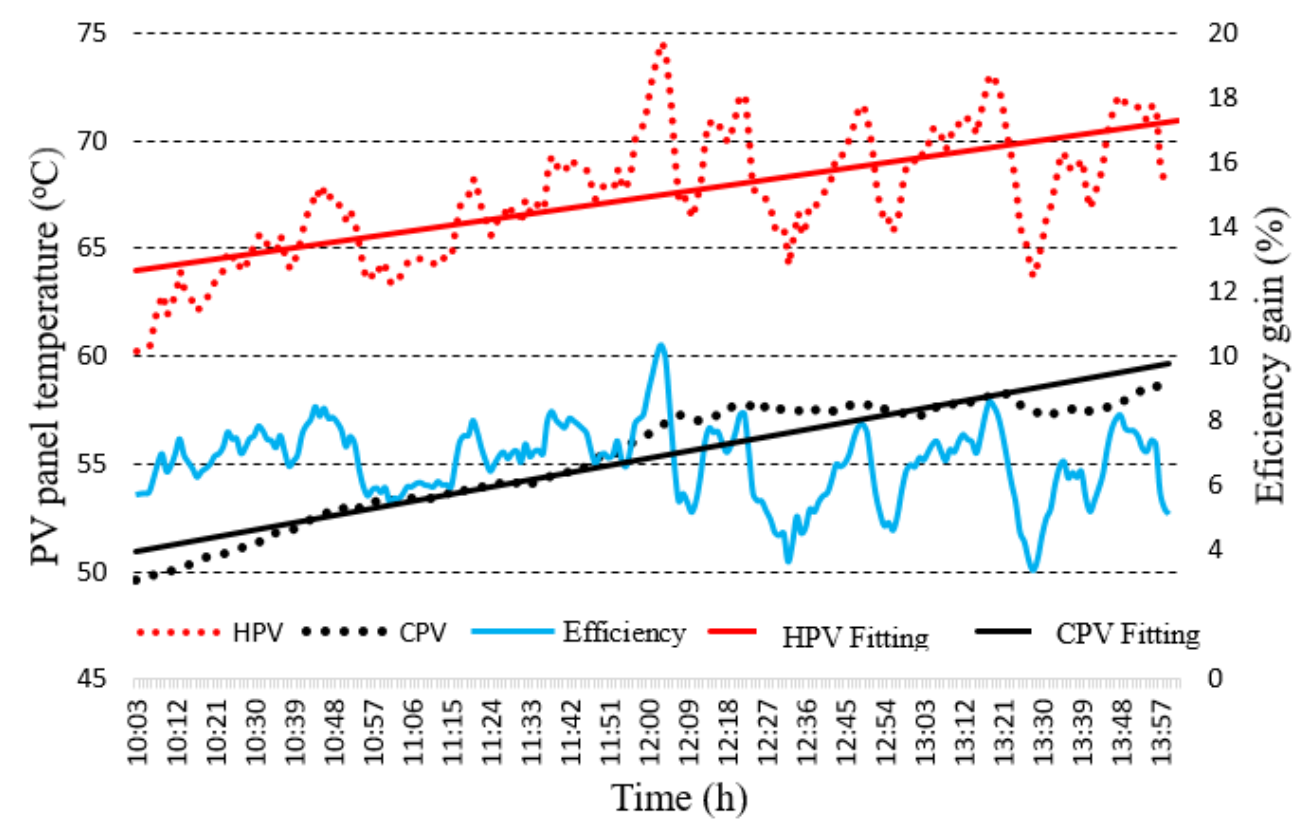

Figure 8. Efficiency gain because of cooling.

It can be seen that the efficiency gain curve looks similar to the HPV temperature curve as the CPV temperature curve has few fluctuations.

\subsection{Effect of Water on Air and PV Panel Temperatures}

The evaporative cooling process is a complex phenomenon that depends not only on weather conditions such as solar radiation, ambient temperature, and humidity but also on various operating conditions. Water flow rate is among these conditions. Therefore, the effect of water flow rate is presented and discussed in this section.

Figure 9 shows the change in air temperature as it flows inside the duct with different water flow rates. The red and black curves represent the temperature of hot and cold PV panels, respectively. The solid, dashed and dotted blue curves represent the inlet, middle and outlet air temperatures inside the duct, respectively. The green line represents the water flow rate. The experiment was conducted at zero water flow rate before 11:25 and after 13:25. Between these time instants, the water flow rate was fixed at $20 \mathrm{~L} / \mathrm{h}$ for about $50 \mathrm{~min}$ and then at $8 \mathrm{~L} / \mathrm{h}$ until 13:25. As air enters the duct, it is subjected to two opposite actions: heating from upper side due to solar radiation and cooling from lower side due to the latent heat of the evaporation process and sensible convection heat transfer due to the temperature difference between air and water temperature. Since the heating process effect is greater than the cooling effect, the net effect is an increase in air temperature as it flows inside the duct.

Before the flow of water, the difference between inlet and outlet air temperatures is around $3{ }^{\circ} \mathrm{C}$ at hour 9:26 and $6{ }^{\circ} \mathrm{C}$ at hour 11:26. However, as water starts flowing, the difference in air temperatures decreases significantly to around $2{ }^{\circ} \mathrm{C}$. Additionally, the cooled PV temperature decreased due to air temperature reduction, which absorbed more heat from the panel. 


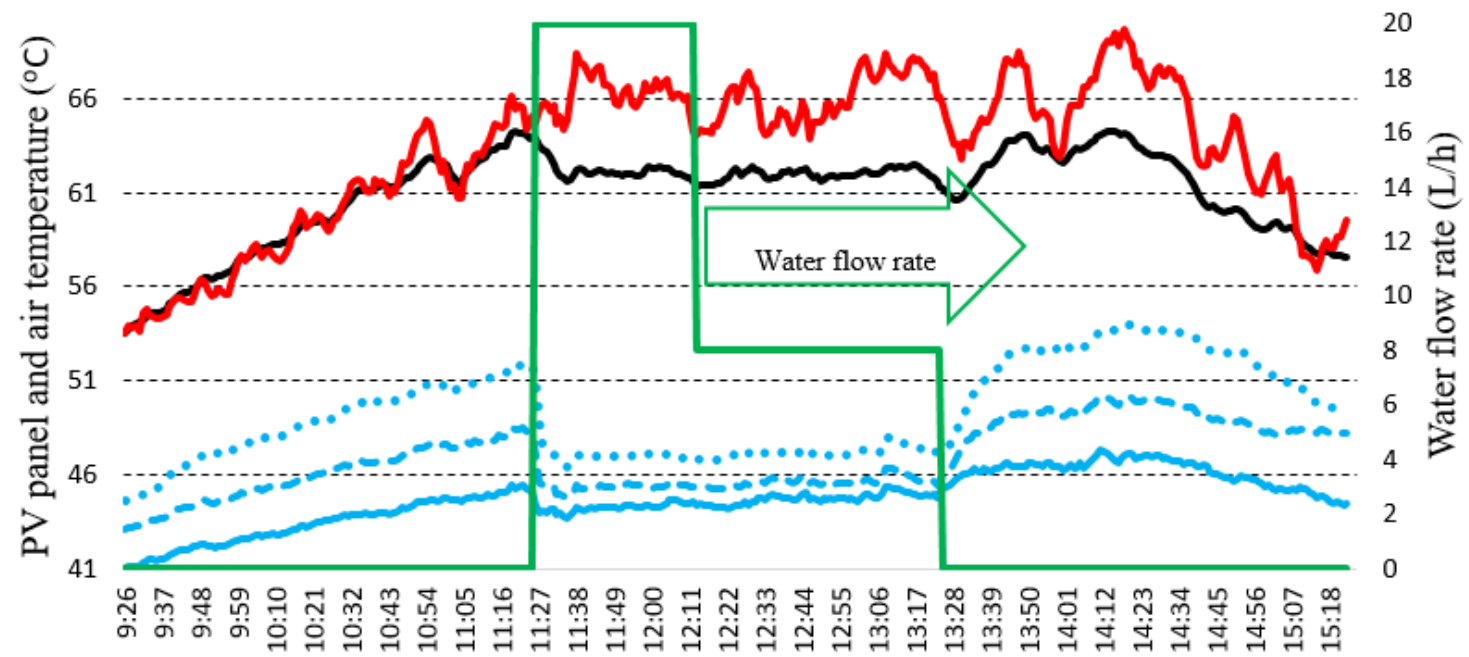

Time (h)

$\cdots$ Air $_{\text {out }} \longrightarrow \mathrm{CPV} \longrightarrow \mathrm{HPV} \longrightarrow \mathrm{Air}_{\mathrm{in}} \longrightarrow \mathrm{Air}_{\text {mid. }} \longrightarrow$ Water flow

Figure 9. Effect of water flow rate on air and cooled PV temperature, 19 August.

Another important observation is that the change in water flow rate does not have a significant role in the cooling process. It was found that when water flow rate decreased, it did not affect the air and PV panel temperatures. At 11:25, the water flow rate was high $>20 \mathrm{~L} / \mathrm{h}$ and after $12: 12$, it decreased to $<10 \mathrm{~L} / \mathrm{h}$, but no clear influence was observed. This implies that the cooling process is controlled by the evaporation phenomenon and can be sustained with a very minimal water to wet the lower plate of the duct without the need for water circulation. This lowers the water requirement and calls for deeper study to find the minimum needed water flow rate. Another important observation concerns the effect of the evaporation cooling sustained after stopping the water flow for a considerable period. This is indicated by the difference between the red and blue curve between 13:25 and 15:06. This shows the possibility of utilizing the evaporation cooling in an intermittent manner to further decrease the water and pumping power requirement.

\subsection{Comparison between the Experimental and Theoretical Results}

This part presents a series of comparisons between the experimental and theoretical results. The proposed model has been used to simulate the temperature distributions of the air, water, and PV panel temperatures under various conditions of solar radiation, air mass flow rate and inlet air and water temperatures.

\subsubsection{PV Temperatures}

Figure 10 shows the temperature of the cooled PV and the reference PV at the following conditions: $\mathrm{G}=943.8 \mathrm{~W} / \mathrm{m}^{2}$, wind speed $(\mathrm{WS})=1.9 \mathrm{~m} / \mathrm{s}, \mathrm{T}_{a i}=39.41^{\circ} \mathrm{C}, \mathrm{T}_{a m}=38.77^{\circ} \mathrm{C}$, relative humidity $\mathrm{RH}=8.8 \%$ and inlet water temperature $T_{l i}=24.43^{\circ} \mathrm{C}$. The experiment data were taken on 20 June at 11:05 am. As shown, there is a fair agreement between the predicted and experimental results.

It can be seen that the agreement between the simulated and experimental temperatures of the cooled PV panel is better than that of the reference PV panel. The root mean square percentage deviation (RMS\%) is $4.68 \%$ for HPV and $0.863 \%$ for CPV. This it may be associated with the effect of wind velocity in which different models and correlations were proposed in the literature to estimate its effect on convection heat loss from the top of PV panels. These models are not generalized for all places and no such models are available specifically for Riyadh. Another factor, which is the wind direction, is not considered in most models of wind effect on PV panels. Since the lower surface of the cooled PV panel is covered by the duct, the wind effect is not as it is in the case of the reference panel. 


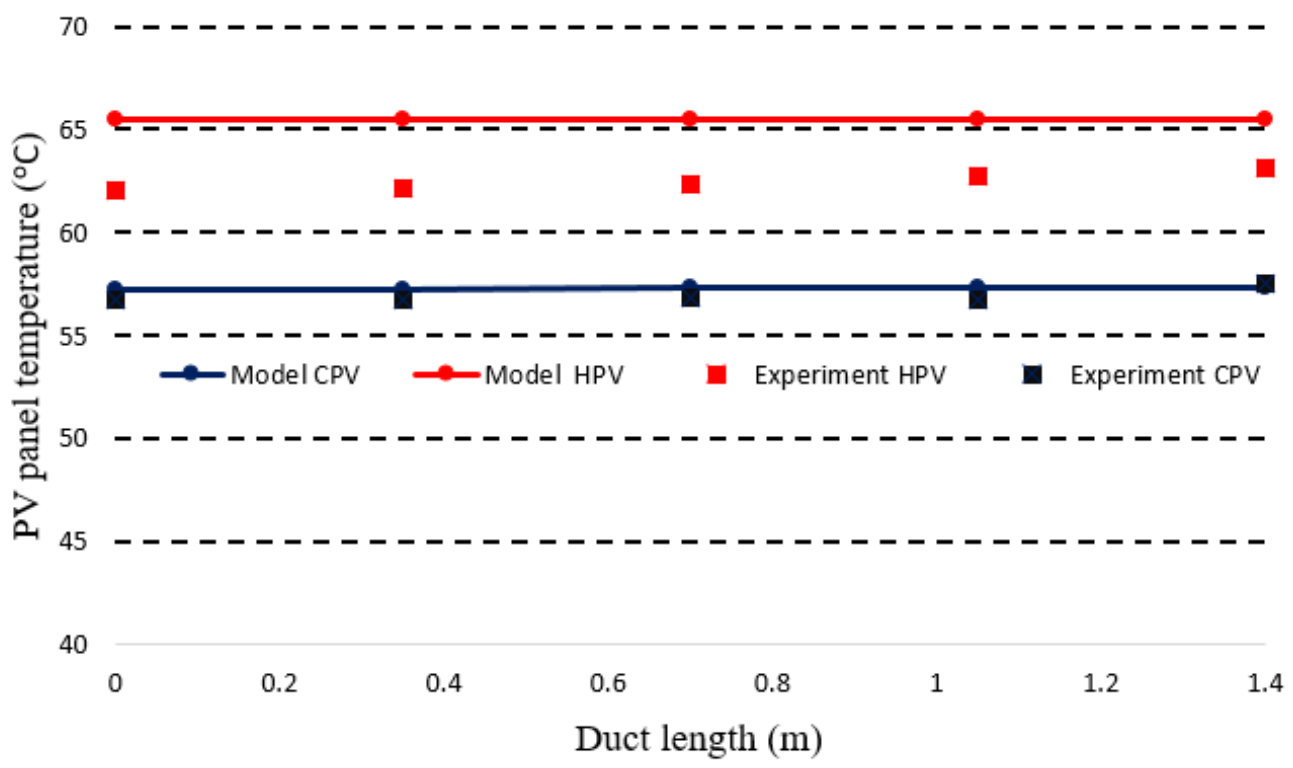

Figure 10. Experimental and simulated cooled and reference PV temperatures on 20 June at 11:05.

Figures 11 and 12 display the temperatures of the cooled PV panel and the reference one for two other different times: at 14:05 on 20 June with RMS\% of 3.58\% for HPV and $1.66 \%$ for CPV and at $13: 50$ on 22 June with RMS\% of $1.18 \%$ for HPV and $1.67 \%$ for $\mathrm{CPV}$, respectively.

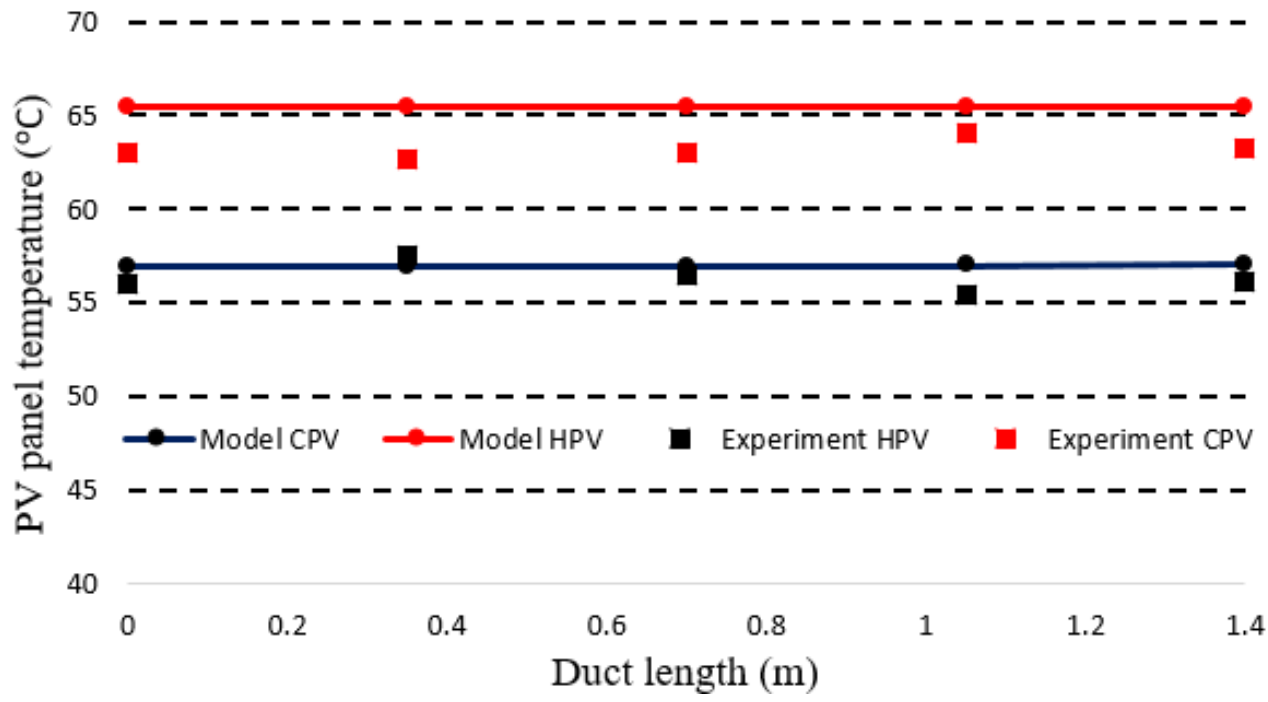

Figure 11. Experimental and simulated cooled and reference PV temperatures on 20 June at 14:05 $\left(\mathrm{G}=797.88 \mathrm{~W} / \mathrm{m}^{2}, \mathrm{~T}_{a m}=42.25^{\circ} \mathrm{C}\right.$, temperature $\left(T_{a i}\right)=43.72{ }^{\circ} \mathrm{C}$, inlet water temperature $\left(T_{l i}\right)=25^{\circ} \mathrm{C}$, wind speed $(\mathrm{WS})=1.2 \mathrm{~m} / \mathrm{s}, \mathrm{RH}=7.99 \%, \dot{m}_{l i}=0.002 \mathrm{~kg} / \mathrm{s}, \dot{m}_{a i}=0.0166 \mathrm{~kg} / \mathrm{s}$ ).

It is worth investigating the agreement of the results for a long period. This is beneficial in ensuring the accuracy and correctness of the models.

Figure 13 depicts a comparison between the model and experimental results for a complete experimentation process on 20 June. The developed model was able to accurately predict the temperature evolution corresponding to the hot and cooled PV panels. The difference between the real readings and the model values is because the model was based on the assumption of energy balance but in the actual real case, the PV module does not reach thermal equilibrium due to weather fluctuation [31]. 


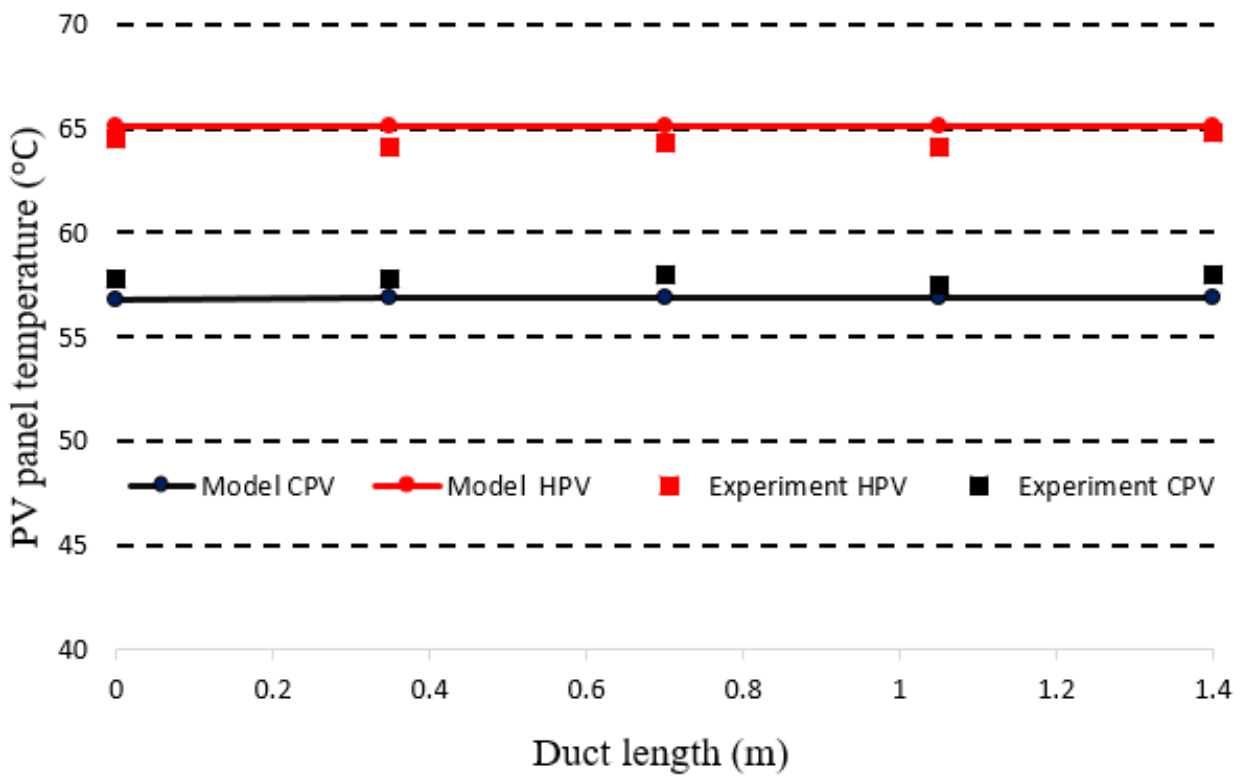

Figure 12. Experimental and simulated cooled and reference PV temperatures on 22 June at 13:50 $\left(\mathrm{G}=809.412 \mathrm{~W} / \mathrm{m}^{2}, \mathrm{~T}_{a m}=41.75{ }^{\circ} \mathrm{C}, \mathrm{T}_{a i}=43.14{ }^{\circ} \mathrm{C}, \mathrm{T}_{l i}=24.47{ }^{\circ} \mathrm{C}, \mathrm{WS}=1.3 \mathrm{~m} / \mathrm{s}, \mathrm{RH}=7.54 \%\right.$, $\left.\dot{m}_{l i}=0.0054 \mathrm{~kg} / \mathrm{s}, \dot{m}_{a i}=0.0166 \mathrm{~kg} / \mathrm{s}\right)$.

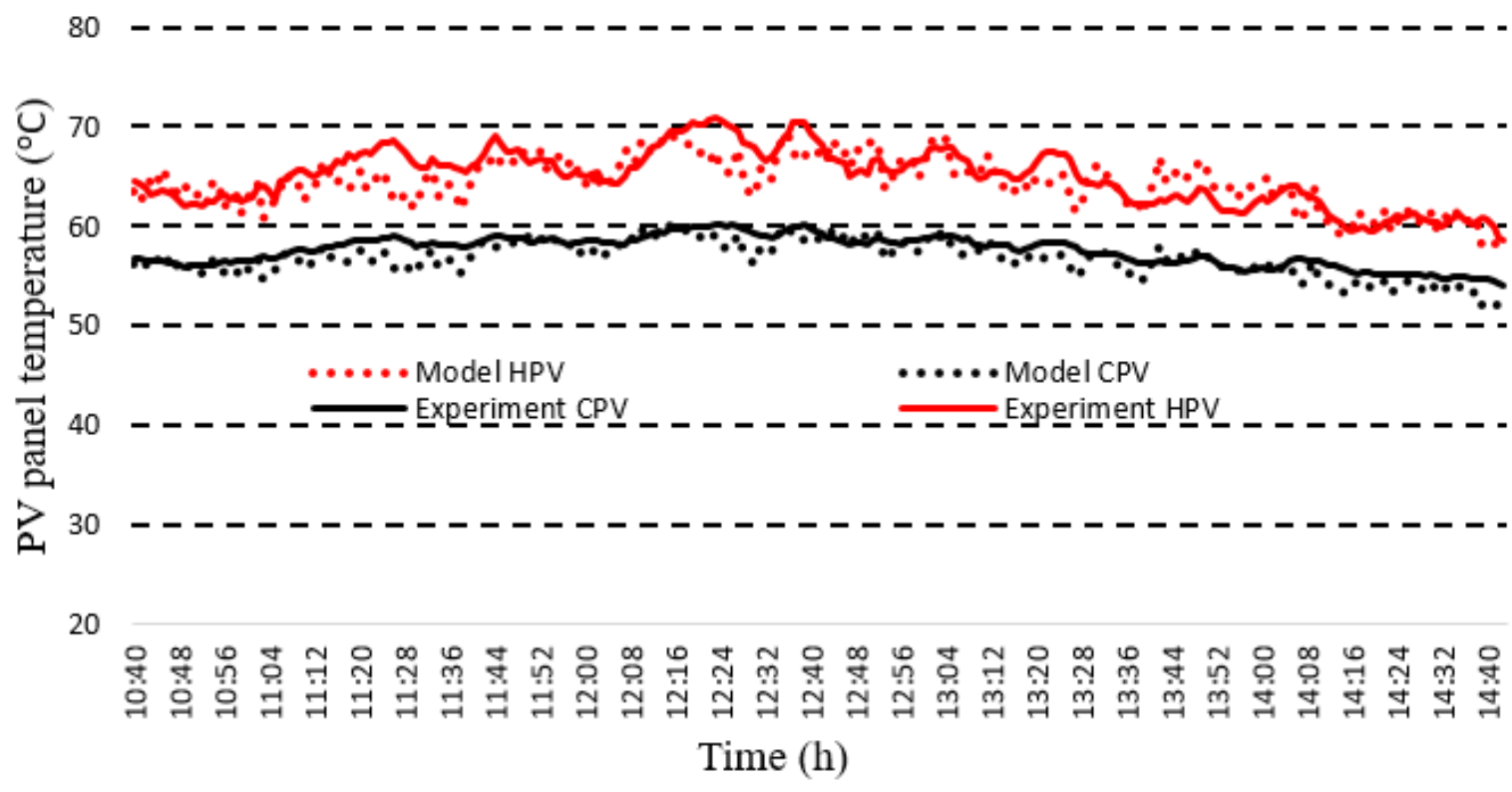

Figure 13. Experimental and simulated cooled and reference PV temperatures on 20 June.

Nevertheless, a very good agreement is observed especially for the cooled PV temperature. The averaged absolute difference (mean absolute error) between the model and experimental values was 1 and 1.8 for the cooled and hot panels' temperature, respectively.

\subsubsection{Water and Air Temperatures}

Figure 14 illustrates air and water temperature changes inside the duct from experimental and simulated results. Referring to Figure 2 helps to understand Figure 14. As air flows inside the duct, it is subjected to a cooling process from the lower side and a heating process from the upper side (Equation (1)). The cooling process is due to two effects: the mass transfer from the saturation layer to the air (indicated by the mass transfer coefficient $U_{m}$ in Figure 2) and the convection heat transfer between the air and the saturation layer 
(indicated by the heat transfer coefficient $U_{a-s}$ in Figure 2). The heating process is because of the convection heat transfer between the air and the PV panel (indicated by the heat transfer coefficient $U_{p v-a}$ in Figure 2). Eventually, the net result gives a humid hot air outlet. However, as the duct is thermally insulated from the outside on the lower side, the water stream just reacts with the saturation layer (Equation (3)) by convection heat transfer (indicated by the heat transfer coefficient $U_{l}$ in Figure 2). The mass transfer from the saturation layer due to evaporation yields a cooling effect on the water stream and, hence, a reduction in its temperature. Apparently, a fair agreement exists between the simulated and experimental results with RMS\% of $2.12 \%$ for air temperature and $5.8 \%$ for water temperature.

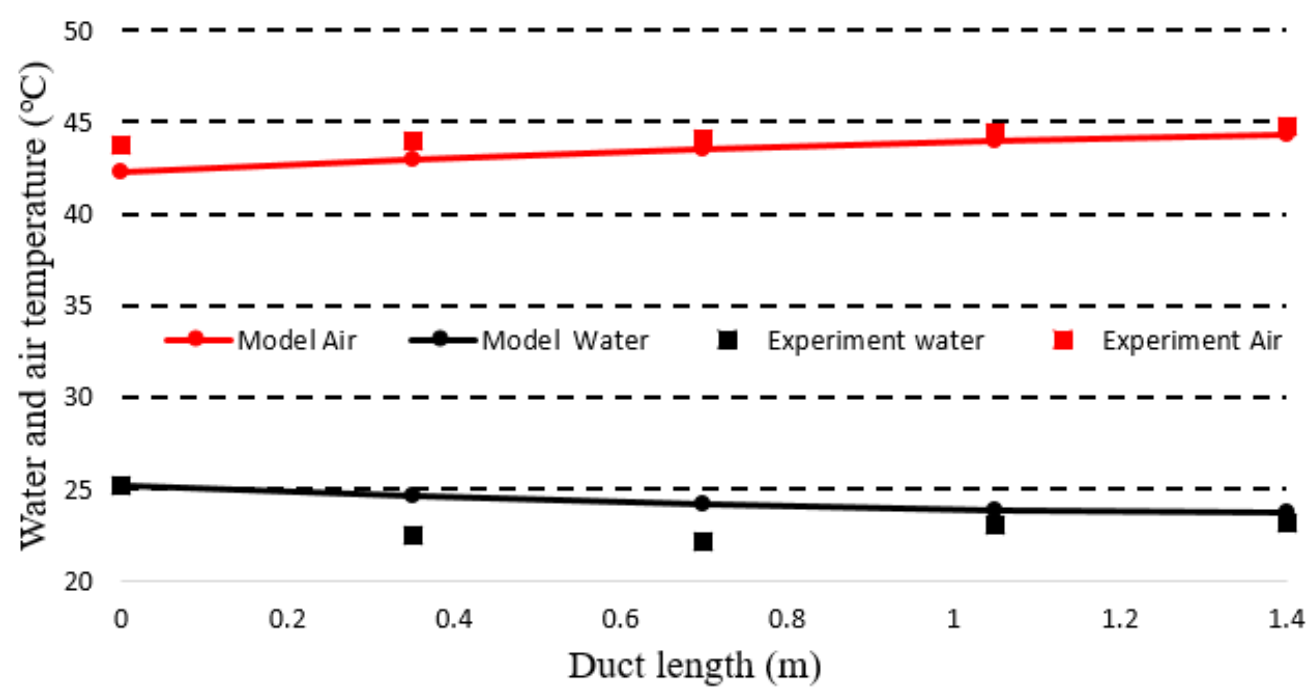

Figure 14. Experimental and simulated air and water temperatures on 20 June at 14:05.

Similar results are shown in Figures 15 and 16 for the same parameters but at different times.

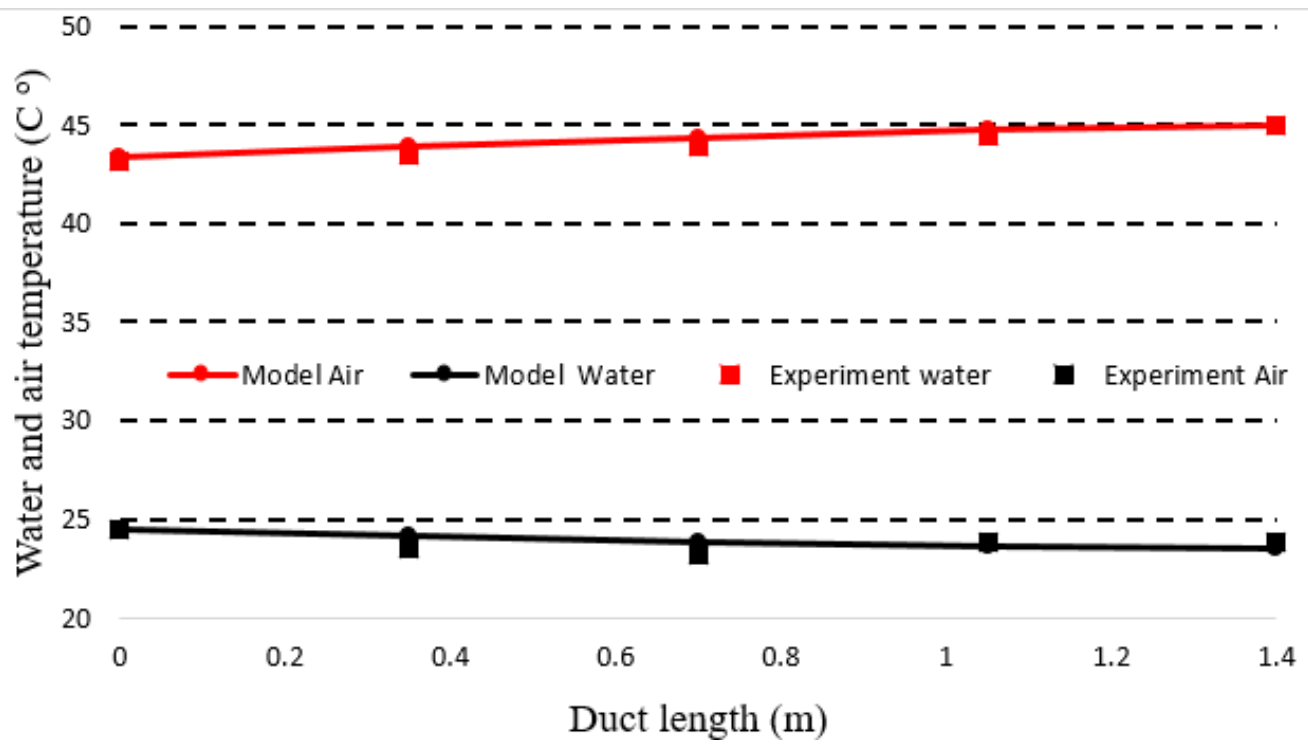

Figure 15. Experimental and simulated air and water temperatures on 22 June at 13:50. 


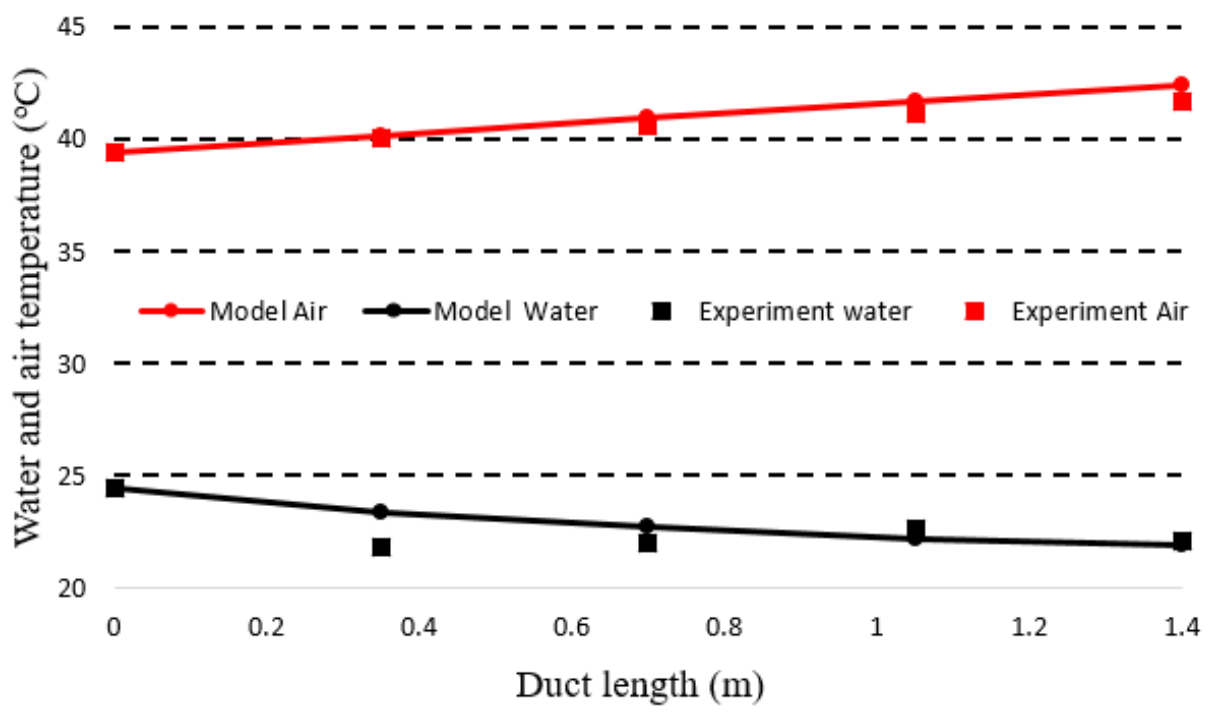

Figure 16. Experimental and simulated air and water temperatures on 20 June at 11:05.

The $\mathrm{RMS} \%$ is $0.78 \%$ and $3.4 \%$ for air temperature and $1.9 \%$ and $1.58 \%$ for water temperature for Figures 15 and 16, respectively.

Finally, the relative humidity of the outlet air can be found using the wet bulb and dry bulb temperatures via the psychrometric chart. For the same conditions of Figure 16, the measured wet bulb temperature was $21.8^{\circ} \mathrm{C}$ and the measured dry bulb was $41.63{ }^{\circ} \mathrm{C}$. These values give a relative humidity of around $15 \%$. Comparing this value with the inlet air relative humidity, which was $9.67 \%$ (measured), the increase in relative humidity was not significant. This was noted during the whole experimentation process for all days.

\subsection{Parametric Study}

The theoretical model is further explored to conduct a parametric study to investigate the effect of various factors on the performance of the cooling process. Figure 17 shows the effect of water and air flow rates on the temperature of the PV panel. Both flow rates affect the panel temperature marginally. This agrees with the results presented in Section 4.3.

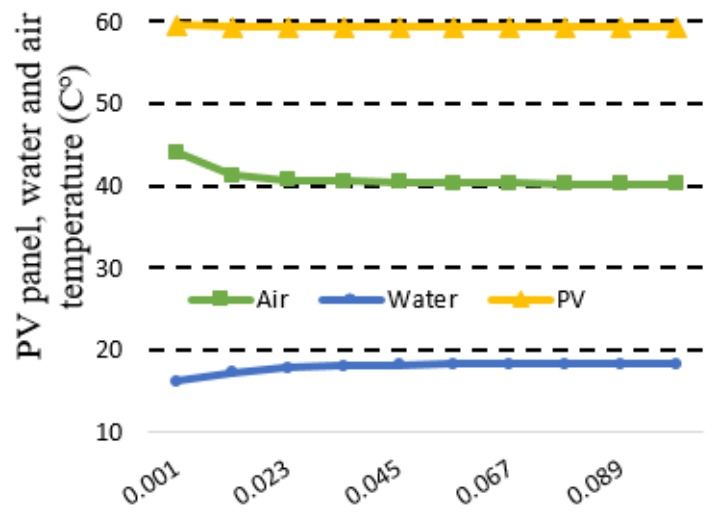

Air flow rate $(\mathrm{kg} / \mathrm{s})$

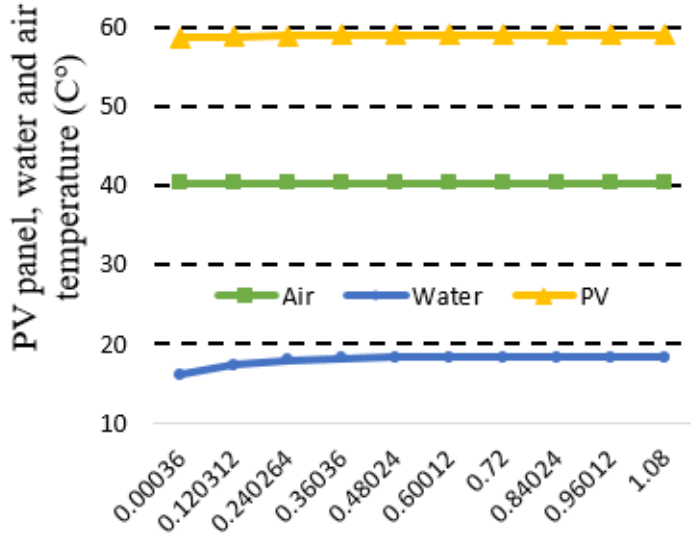

Water flow rate $(\mathrm{L} / \mathrm{h})$

Figure 17. Effect of water and air flow rates on panel's temperature.

Therefore, it can be concluded that very little water is needed for the cooling process, just to wet the lower side on the duct. On the other side, the choice of the smallest air flow rate is a sensitive question since it depends on the pressure losses induced inside the duct. 
Figure 18 shows the behavior of the cooling system at different solar radiations. The effect of solar radiation on the PV modules and outlet air temperatures is noticeable, though the water temperature was not affected. At lower solar radiation, the outlet air temperature is lower than the inlet temperature. This implies that the cooling effect between the water and flowing air is larger than the heating effect due to solar energy. As solar radiation increases, its impact is dominant. Another observation is that the difference between the cooled and reference PV modules is larger at high solar radiation $\left(\sim 9{ }^{\circ} \mathrm{C}\right)$ and is smaller at low radiation $\left(\sim 5.5^{\circ} \mathrm{C}\right)$. Thus, the proposed cooling method is effective at the midday hours when solar radiation is high, and the temperature of the PV panels is elevated.

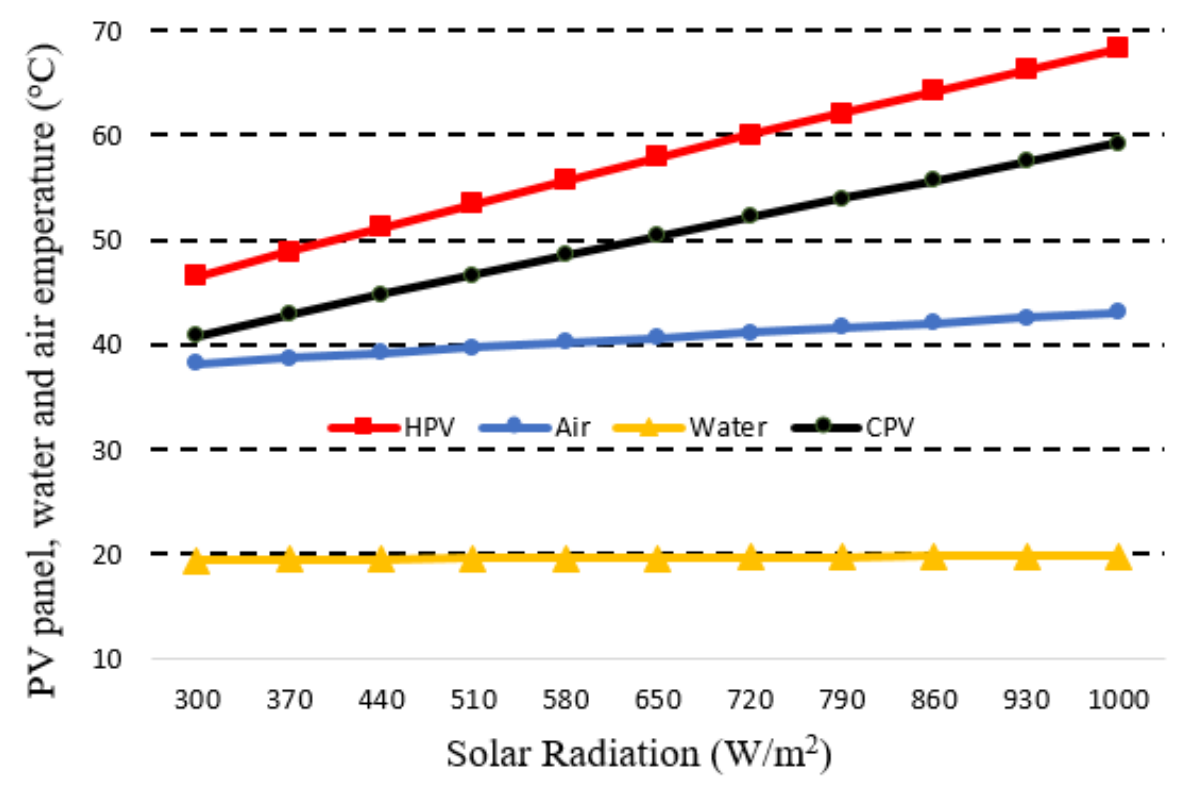

Figure 18. Effect of solar radiation on the cooling system at $T_{l i}=20^{\circ} \mathrm{C}$ and $T_{a i}=40^{\circ} \mathrm{C}$.).

\subsection{Fan and Water Pumping Power Consumption}

The power consumption of the fan and pump was not measured during the experimental work because these systems were overrated, and the main purpose was to prove the concept and study its technical feasibility. However, the results give some hints regarding this. First, the experiment operation does not require any pumping for water flow inside the duct because the water flows downward due to gravity. Yet, the water needs pumping power to fill the tank before the operation. If there is any adjacent water storage facility (as is the case in many cities in some countries such as Saudi Arabia where every house has a big water tank on the roof), the water can be supplied from this tank. Additionally, as shown in Figures 9 and 17, the water flow rate can be decreased to very small values without affecting the cooling impact and hence it can be deduced that the water requirement for this design is very little. It is just required to wet the cloth piece inside the duct without circulation. Therefore, a few drops of water are enough and the filling process (if any) of the associated tank requires a small pump that will run intermittently with long off-operation and very short on-operation. This discussion implies very low pumping power consumption. Moreover, optimization of the water flow rate can reduce the water quantity and pumping requirement.

Concerning the fan power consumption, the fan power $W_{f}$ can be calculated using the following equation [32]:

$$
W_{f}=\dot{V} P_{D}
$$

where $\dot{V}$ is the volume flow rate and $P_{D}$ is the pressure drop. $P_{D}$ can be calculated as follows [32]:

$$
P_{D}=f L \rho v /\left(2 D_{h}\right)
$$


where $f$ is the friction factor $(96 / \operatorname{Re}$ [32]), $L$ is the duct length $(1.4 \mathrm{~m}), \rho$ is the air density $\left(1.25 \mathrm{~kg} / \mathrm{m}^{3}\right), D_{h}$ is the hydraulic diameter of the duct $(0.0574 \mathrm{~m})$, and $v$ is the air velocity $(0.8 \mathrm{~m} / \mathrm{s})$. Using Equations (17) and (18), the value of $W_{f}$ was found to be equal to 0.0051 watt. Comparing this value by the power gain $W_{g}$ due to the cooling can be calculated as follows:

$$
W_{g}=\text { efficiency gain } * \text { PV panel rated power } / 100
$$

Efficiency gain is calculated using Equation (15). From Figure 8, the lowest value of the efficiency gain is $3.644 \%$. Putting this value in Equation (19), $W_{g}$ equals 4.73 watt, which is much larger than the fan power requirement. We can, therefore, conclude that this design is economically feasible.

\subsection{Uncertainty Analysis}

The uncertainty analysis was conducted to ensure the reliability of the results. The uncertainty analysis was conducted for the thermocouples as they are the main measuring instrument used in this study. The total error of the thermocouples was found to be $1.51{ }^{\circ} \mathrm{C}$, which is far lower than the readings of the thermocouples during the experimentation process. Detailed calculation can be found in ref. [9].

\section{Conclusions}

The performance of the PV panels drops significantly with the increase in the operating temperature. Different techniques were proposed to resolve this problem. Using evaporative cooling in dry climates such as Riyadh is a simple and very effective way to reduce the PV panels' temperature. A sequence of evaporative cooling experimentations was conducted and the enhancement in electrical power was investigated by measuring the open-circuit voltage. The experimentation process was carried out for a long time in the summer under real environmental conditions (outdoor test). It should be noted that these experiments were carried out under real outdoor environmental conditions in very a hot climate; on the actual normal size of PV panels at actual inclination and mounted for several days. The temperature of the PV panel was decreased by more than $10{ }^{\circ} \mathrm{C}$ and power improvement reached $5 \%$. However, the cooling performance was stable and showed a competitive achievement. Additionally, a theoretical model on the heat and mass transfer in a wetted channel was developed and systematically validated using the experimental data. Fair agreements have been found between the theoretical and experimental results. The obtained results show that the evaporative cooling process is effective, economically feasible, and the water quantity required is very little (just to ensure a uniform wetting of the surface). Furthermore, an important observation is that the evaporative cooling reduced the PV temperature fluctuation and thus improved the electrical output stability. This feature is highly desired in electrical power systems with high solar PV energy penetration.

Author Contributions: Conceptualization, J.O.; methodology, software, validation, formal analysis, investigation, writing, original draft preparation, and visualization, Z.A.H.; writing-review and editing, J.O. and Z.K.; supervision, J.O. and Z.K.; project administration, J.O.; funding acquisition, Z.K. All authors have read and agreed to the published version of the manuscript.

Funding: This research was funded by the "Ministry of Education" in Saudi Arabia, grant number: IFKSURG-292.

Data Availability Statement: The data was measured and collected by the authors and it is not available online.

Acknowledgments: The authors extend their appreciation to the Deputyship for Research and Innovation, the "Ministry of Education" in Saudi Arabia for funding this research work through the project number IFKSURG-292.

Conflicts of Interest: The authors declare no conflict of interest. The funders had no role in the design of the study; in the collection, analyses, or interpretation of data; in the writing of the manuscript, or in the decision to publish the results. 


\section{Nomenclature, Subscripts and Special Symbols}

\begin{tabular}{|c|c|}
\hline$C p$ & specific heat at constant pressure $\left[\mathrm{J} \mathrm{kg}^{-1} \mathrm{~K}^{-1}\right]$ \\
\hline CPV & cold PV panel (cooled panel) \\
\hline$D_{h}$ & hydraulic diameter \\
\hline EXP & experimental data \\
\hline$f$ & friction factor \\
\hline G & solar radiation $\left[\mathrm{Wm}^{-2}\right]$ \\
\hline$H$ & height $[\mathrm{m}]$ \\
\hline$h$ & specific enthalpy $\left[\mathrm{J} \mathrm{kg}^{-1}\right]$ \\
\hline$h_{\mathrm{fg}}$ & specific enthalpy of evaporation $\left[\mathrm{J} \mathrm{kg}^{-1}\right]$ \\
\hline HPV & hot PV panel (reference panel) \\
\hline$L$ & length $[\mathrm{m}]$ \\
\hline Le & Lewis number \\
\hline$\dot{m}$ & mass flow rate $\left(\mathrm{kg} \mathrm{s}^{-1}\right)$ \\
\hline $\mathrm{P}$ & width $[\mathrm{m}]$ \\
\hline$P_{D}$ & pressure drop $[\mathrm{Pa}]$ \\
\hline$q$ & heat flux $\left[\mathrm{Wm}^{-2}\right]$ \\
\hline $\operatorname{Re}$ & Reynold's number \\
\hline $\mathrm{RH}$ & relative humidity \\
\hline$\rho$ & density $\left[\mathrm{kg} / \mathrm{m}^{3}\right]$ \\
\hline $\mathrm{T}$ & temperature $\left[{ }^{\circ} \mathrm{C}\right]$ \\
\hline TC & thermocouples \\
\hline $\mathrm{U}$ & coefficient of heat transfer $\left[\mathrm{Wm}^{-2} \mathrm{~K}^{-1}\right]$ \\
\hline Um & coefficient of mass transfer $\left[\mathrm{kgm}^{-2} \mathrm{~s}^{-1}\right]$ \\
\hline V & voltage $[\mathrm{V}]$ \\
\hline$\dot{V}$ & volume flow rate $\left[\mathrm{m}^{3} / \mathrm{s}\right]$ \\
\hline$v$ & air velocity $[\mathrm{m} / \mathrm{s}]$ \\
\hline Ws & saturation humidity (kg of vapor/kg of air) \\
\hline Wf & fan power \\
\hline $\mathrm{W}_{\mathrm{g}}$ & power gain \\
\hline WS & wind speed $\mathrm{ms}^{-1}$ \\
\hline \multirow[t]{2}{*}{$x$} & axial coordinate $(\mathrm{m})$ \\
\hline & Subscripts \\
\hline$a m$ & ambient temperature \\
\hline c & actual \\
\hline $\operatorname{conv}$ & convection \\
\hline$i$ & inlet conditions \\
\hline$l$ & liquid (water) \\
\hline$m p$ & maximum power \\
\hline oc & open circuit \\
\hline pv & PV panel \\
\hline$R$ & reference \\
\hline$r$ & radiation \\
\hline$s$ & saturated layer \\
\hline SC & short circuit \\
\hline \multirow[t]{2}{*}{$v$} & water vapor \\
\hline & Special Symbols \\
\hline$\beta$ & PV panels efficiency temperature coefficient \\
\hline$\varepsilon$ & emissivity coefficient \\
\hline$\rho$ & density $\left[\mathrm{kg} / \mathrm{m}^{3}\right]$ \\
\hline$\sigma$ & Boltzmann's constant \\
\hline$\eta$ & efficiency \\
\hline$\tau \alpha$ & optical efficiency \\
\hline
\end{tabular}

\section{References}

1. Solar Energy. Available online: https://www.irena.org/solar (accessed on 20 December 2020).

2. Elminshawy, N.A.; Mohamed, A.; Morad, K.; Elhenawy, Y.; Alrobaian, A.A. Performance of PV panel coupled with geothermal air cooling system subjected to hot climatic. Appl. Therm. Eng. 2019, 148, 1-9. [CrossRef] 
3. Solanki, C.; Sangani, C.; Gunashekar, D.; Antony, G. Enhanced heat dissipation of V-trough PV modules for better performance. Sol. Energy Mater. Sol. Cells 2008, 92, 1634-1638. [CrossRef]

4. Fakouriyan, S.; Saboohi, Y.; Fathi, A. Experimental analysis of a cooling system effect on photovoltaic panels' efficiency and its preheating water production. Renew. Energy 2019, 134, 1362-1368. [CrossRef]

5. Abdollahi, N.; Rahimi, M. Potential of water natural circulation coupled with nano-enhanced PCM for PV module cooling. Renew. Energy 2020, 147, 302-309. [CrossRef]

6. Luboń, W.; Pełka, G.; Janowski, M.; Pajak, L.; Stefaniuk, M.; Kotyza, J.; Reczek, P. Assessing the Impact of Water Cooling on PV Modules Efficiency. Energies 2020, 13, 2414. [CrossRef]

7. Salem, M.; Elsayed, M.; Abd-Elaziz, A.; Elshazly, K. Performance enhancement of the photovoltaic cells using Al2O3/PCM mixture and/or water cooling-techniques. Renew. Energy 2019, 138, 876-890. [CrossRef]

8. Sarafraz, M.; Safaei, M.R.; Leon, A.S.; Tlili, I.; Alkanhal, T.A.; Tian, Z.; Goodarzi, M.; Arjomandi, M. Experimental investigation on thermal performance of a PV/T-PCM (photovoltaic/thermal) system cooling with a PCM and nanofluid. Energies 2019, 12, 2572. [CrossRef]

9. Haidar, Z.A.; Orfi, J.; Kaneesamkandi, Z. Experimental investigation of evaporative cooling for enhancing photovoltaic panels efficiency. Results Phys. 2018, 11, 690-697. [CrossRef]

10. Kadhim, A.M.; Aljubury, I.M.A. Experimental Evaluation of Evaporative Cooling for Enhancing Photovoltaic Panels Efficiency Using Underground Water. J. Eng. 2020, 26, 14-33. [CrossRef]

11. Alami, A.H. Effects of evaporative cooling on efficiency of photovoltaic modules. Energy Convers. Manag. 2014, 77, 668-679. [CrossRef]

12. Abdallah, S.R.; Saidani-Scott, H.; Benedi, J. Experimental study for thermal regulation of photovoltaic panels using saturated zeolite with water. Sol. Energy 2019, 188, 464-474. [CrossRef]

13. Borkar, D.S.; Prayagi, S.V.; Gotmare, J. Performance evaluation of photovoltaic solar panel using thermoelectric cooling. Int. J. Eng. Res. 2014, 3, 536-539. [CrossRef]

14. Zhu, L.; Raman, A.P.; Fan, S. Radiative cooling of solar absorbers using a visibly transparent photonic crystal thermal blackbody. Proc. Natl. Acad. Sci. USA 2015, 112, 12282-12287. [CrossRef] [PubMed]

15. Firoozzadeh, M.; Shiravi, A.H.; Shafiee, M. Different methods of using phase change materials (PCMs) as coolant of photovoltaic modules: A review. J. Energy Manag. Technol. 2020, 4, 30-36.

16. Al-Waeli, A.H.; Kazem, H.A.; Chaichan, M.T.; Sopian, K. Photovoltaic/Thermal (PV/T) Systems Principles, Design, and Applications; Springer Nature: Berlin, Germany, 2019.

17. Cotfas, D.; Cotfas, P. Multiconcept methods to enhance photovoltaic system efficiency. Int. J. Photoenergy 2019, $2019,1905041$. [CrossRef]

18. Ramkumar, R.; Kesavan, M.; Raguraman, C.; Ragupathy, A. Enhancing the Performance of Photovoltaic Module Using Clay Pot Evaporative Cooling Water. In Proceedings of the 2016 International Conference on Energy Efficient Technologies for Sustainability (ICEETS), Nagercoil, India, 7-8 April 2016; pp. 217-222.

19. Drabiniok, E.; Neyer, A. Micro porous polymer foil for application in evaporation cooling. Microsyst. Technol. 2014, 20, 1913-1918. [CrossRef]

20. Lucas, M.; Aguilar, F.; Ruiz, J.; Cutillas, C.; Kaiser, A.; Vicente, P. Photovoltaic Evaporative Chimney as a new alternative to enhance solar cooling. Renew. Energy 2017, 111, 26-37. [CrossRef]

21. Lucas, M.; Ruiz, J.; Aguilar, F.; Cutillas, C.; Kaiser, A.; Vicente, P. Experimental study of a modified evaporative photovoltaic chimney including water sliding. Renew. Energy 2019, 134, 161-168. [CrossRef]

22. Boulama, K.; Galanis, N.; Orfi, J. Heat and mass transfer between gas and liquid streams in direct contact. Int. J. Heat Mass Transf. 2004, 47, 3669-3681. [CrossRef]

23. Loveday, D.L.; Taki, A.H. Convective heat transfer coefficients at a plane surface on a full-scale building facade. Int. J. Heat Mass Transf. 1996, 39, 1729-1742.

24. Jones, A.D.; Underwood, C.P. A Thermal Model for Photovoltaic Systems. Sol. Energy 2001, 70, 349-359. [CrossRef]

25. Fan, M.; Vittal, V.; Heydt, G.T.; Ayyanar, R. Probabilistic power flow studies for transmission systems with photovoltaic generation using cumulants. IEEE Trans. Power Syst. 2012, 27, 2251-2261. [CrossRef]

26. Nakanishi, F.; Ikegami, T.; Ebihara, K.; Kuriyama, S.; Shiota, Y. Modeling and operation of a $10 \mathrm{~kW}$ photovoltaic power generator using equivalent electric circuit method. In Proceedings of the Conference Record of the Twenty-Eighth IEEE Photovoltaic Specialists Conference-2000 (Cat. No. 00CH37036), Anchorage, AK, USA, 15-22 September 2000; pp. $1703-1706$.

27. Rahman, S.; Bouzguenda, M. A model to determine the degree of penetration and energy cost of large scale utility interactive photovoltaic systems. IEEE Trans. Energy Convers. 1994, 9, 224-230. [CrossRef]

28. Hussein, K.; Muta, I.; Hoshino, T.; Osakada, M. Maximum photovoltaic power tracking: An algorithm for rapidly changing atmospheric conditions. IEE Proc. -Gener. Transm. Distrib. 1995, 142, 59-64. [CrossRef]

29. Lin, C.-H.; Hsieh, W.-L.; Chen, C.-S.; Hsu, C.-T.; Ku, T.-T.; Tsai, C.-T. Financial analysis of a large-scale photovoltaic system and its impact on distribution feeders. IEEE Trans. Ind. Appl. 2011, 47, 1884-1891. [CrossRef]

30. Assoa, Y.; Menezo, C.; Fraisse, G.; Yezou, R.; Brau, J. Study of a new concept of photovoltaic-thermal hybrid collector. Sol. Energy 2007, 81, 1132-1143. [CrossRef] 
31. Du, Y.; Fell, C.J.; Duck, B.; Chen, D.; Liffman, K.; Zhang, Y.; Gu, M.; Zhu, Y. Evaluation of photovoltaic panel temperature in realistic scenarios. Energy Convers. Manag. 2016, 108, 60-67. [CrossRef]

32. Cengel, Y.A.; Klein, S.; Beckman, W. Heat Transfer: A Practical Approach; WBC McGraw-Hill Boston: Boston, MA, USA, 1998; Volume 141. 